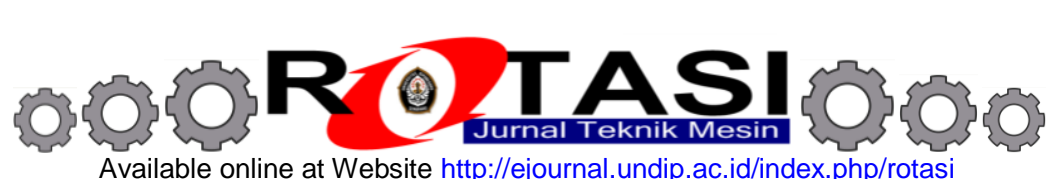

Available online at Website http://ejournal.undip.ac.id/index.php/rotasi

\title{
ANALISIS TEGANGAN, DEFLEKSI, DAN FAKTOR KEAMANAN PADA PEMODELAN FOOTSTEP HOLDER SEPEDA MOTOR "Y” BERBASIS SIMULASI ELEMEN HINGGA
}

\author{
Slamet Khoeron, *Imam Syafa'at, Darmanto \\ Jurusan Teknik Mesin, Fakultas Teknik, Universitas Wahid Hasyim \\ Jl. Menoreh Tengah X/22, Sampangan, Semarang 50236 \\ *emaili.syafaat@gmail.com
}

\begin{abstract}
ABSTRAK
Sepeda motor banyak dipilih masyarakat sebagai moda transportasi. Untuk itu diperlukan komponenkomponen sepeda motor yang aman digunakan bagi pengendara. Footstep holder merupakan komponen yang mempunyai fungsi untuk memegang pijakan footstep pengendara sepeda motor. Tujuan dari penelitian ini adalah untuk menganalisa berbagai pembebanan pada footstep holder menggunakan pemodelan dengan bantuan software Autodesk Inventor Professional 2013. Berbagai pembebanan dilakukan pada pemodelan dengan berbagai kondisi. Pembebanan tersebut meliputi pembebanan dengan kondisi pengendara duduk dengan kaki bertumpu pada footstep, pengendara berdiri pada footstep, motor jatuh kesamping, footstep tertabrak dari belakang, footstep tertabrak dari depan dan motor djatuh kesamping dengan dinaiki dua pengendara. Hasil yang didapat setelah dilakukan analisa dalam berbagai kondisi secara berturut-turut adalah tegangan von mises yaitu 9,298MPa, 32,54MPa, 233,7MPa, 246,022MPa, 203MPa, 468,9MPa, yang kedua defleksi yaitu $0,00829 \mathrm{~mm}, 0,02905 \mathrm{~mm}, 0,6159 \mathrm{~mm}, 0,616 \mathrm{~mm}, 0,592 \mathrm{~mm}, 1,32 \mathrm{~mm}$ dan yang ketiga faktor keamanan yaitu diatas $15,8,45,1,18,1,12,1,35,0,59$. Pada pembebanan dengan kondisi motor jatuh kesamping dengan dinaiki dua pengendara beresiko besar terhadap patahnya footstep holder dengan tegangan von mises 468,9MPa dan mempunyai faktor keamanan yang rendah 0,59 dengan defleksi 1,32mm.
\end{abstract}

Kata kunci: footstep holder, tegangan von mises, defleksi, faktor keamanan

\section{PENDAHULUAN}

Sepeda motor banyak dipilih masyarakat sebagai moda transportasi. Minimnya perlindungan yang diberikan oleh sepeda motor mengakibatkan makin banyak korban pada saat terjadi kecelakaan. Sehingga perlindungan perlu dilakukan sebagai upaya yang tepat untuk keselamatan oleh pengguna sepeda motor, karena pengemudi sepeda motor cenderung berperilaku buruk dijalan. Untuk itu diperlukan komponen-komponen sepeda motor yang aman digunakan pengendara. Secara visual komponen ini mempunyai bentuk yang menarik, tatapi bentuk tersebut belum menjamin mempunyai kekuatan struktural yang baik. Bahkan beberapa kasus ada footstep holder yang patah seperti terlihat pada Gambar 1. Penyebab patah yang ditunjukkan pada Gambar 1 ada diakibatkan karena pengendara kurang berhati-hati dalam mengemudi dengan berbagai posisi.

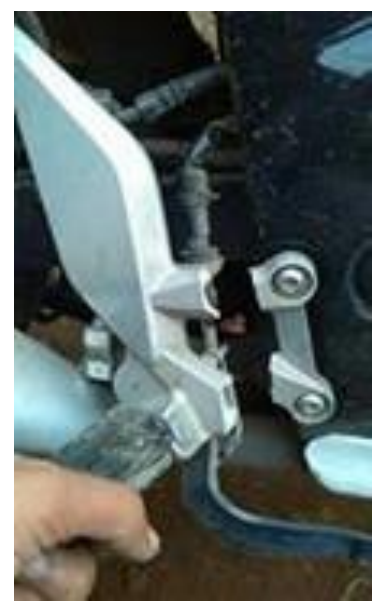

Gambar 1. Footstep holder patah [1]

Proses terbentuknya sebuah produk secara umum melewati tiga tahapan. Tahapan-tahapan tersebut adalah perancangan teknik, manufaktur, kondisi pemakaian. Antara ketiga proses tersebut saling berkaitan untuk menghasilkan sebuah produk yang handal dengan resiko kegagalan yang kecil. Menurut Tawancy dkk. [2] kegagalan sebuah produk bisa dianalisa dari ketiga tahapan. Adapun mata rantai yang paling lemah dari proses tersebut adalah pada bagian kondisi pemakaian dalam memberikan masukan kepada bagaian perancangan teknik bagi proses desainnya. 
Footstep holder merupakan sepasang komponen pada kendaraan sepeda motor yang mempunyai fungsi untuk memegang pijakan bagi pengendra dan bagi pembonceng. Sambas [3] telah merancang dan membuat footstep holder, langkah awal dimulai dari evaluasi rancangan, simulasi dengan Solidworks 2004 hingga di hasilkan rancangan yang optimal. Bahan yang digunakan adalah Al-Si. Hasilnya perubahan rancangan dengan mengurangi bahan tanpa mengabaikan kekuatan yang aman.

Dudukan stang sepeda motor menerima gaya beban dari bobot mesin dan penumpang pada kondisi statis. Akibatnya akan timbul deformasi dan tegangan terdistribusi pada penampang struktur tersebut. Untuk mengetahui tegangan strukturnya perlu dilakukan simulasi dengan software CATIA V5R14. Hasilnya tegangan maksimum analisa komputer antara dudukan segitiga stang sepeda motor sebesar 8,48 x $10 \mathrm{~N} / \mathrm{m}^{2}$ sebelum mengalami modifikasi dan 7,57 $\mathrm{x} 10^{6} \mathrm{~N} / \mathrm{m}^{2}$ setelah dimodifikasi [4].

Analisa distribusi tegangan dari struktur batang penghubung sebuah kendaraan roda dua dengan material baja AISI 1045 juga telah diteliti. Dianalisa berdasarkan pada pengukuran secara manual. Selanjutnya digambarkan dan dianalisis di Solidworks 2007. Dari hasil analisis menunjukkan bahwa tegangan maksimum yang terjadi masih dibawah harga dari yield strength. Semakin besar harga yield strength terhadap tegangan maksimal maka struktur itu akan lebih aman digunakan [5]. Dari berbagai kajian literatur diatas, belum terlihat adanya studi tentang kekuatan footstep holder. Tujuan dari penelitian ini adalah untuk mengetahui distribusi tegangan von mises, defleksi, dan faktor keamanan dari komponen tersebut.

\section{METODE PENELITIAN}

Dalam penelitian ini, peneliti melakukan analisa berbagai pembebanan pada footstep holder dengan metode elemen hingga supaya diperoleh tegangan, defleksi, dan faktor keamanan dengan maenggunakan bahan material paduan Alumunium 6061 yang tersedia pada software [6]. Komponen sepeda motor yang akan diteliti adalah footstep holder "Y" seperti terlihat pada Gambar 2.
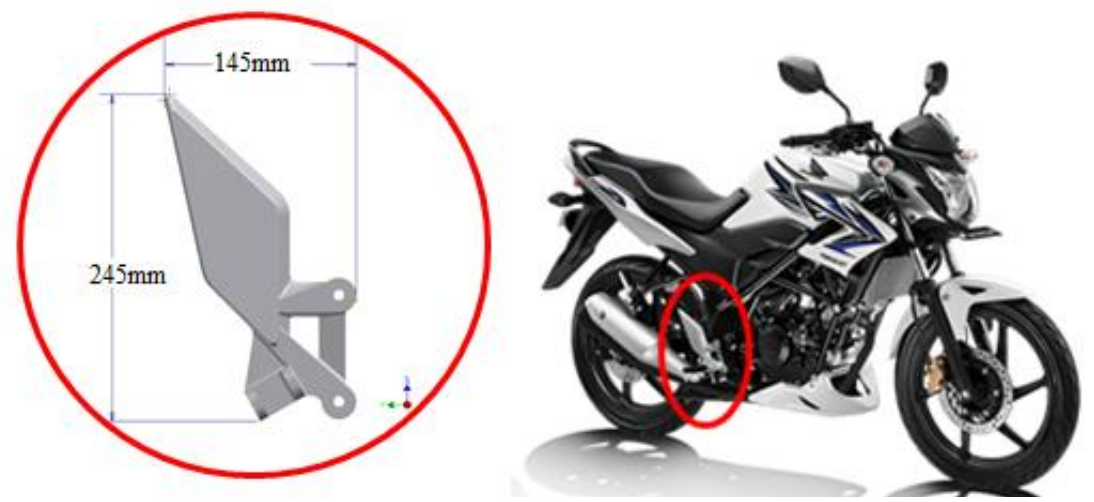

Gambar 2. Footstep holder motor "Y"

Langkah selanjutnya komponen tersebut dianalisa berdasarkan pada pengukuran secara manual dengan menggunakan alat bantu jangka sorong. Setelah geometri selesai dilakukan pengukuran maka selanjutnya geometri yang terlihat pada Gambar 2 dimodelkan dan dianalisa dengan menggunakan Autodesk Inventor Professional 2013 seperti terlihat pada Gambar 3.

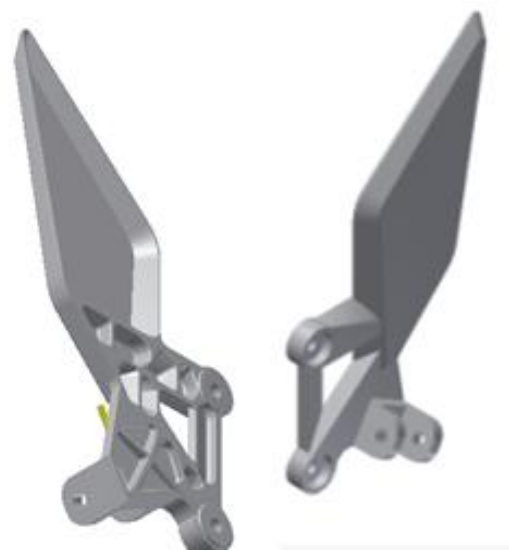

Gambar 3. Pemodelan footstep holder dengan Autodesk Inventor Professional 2013 
Dalam melakukan pembebanan pada pemodelan bagian komponen sepeda motor footstep holder ini, peneliti terlebih dahulu melakukan validasi dan boundry conditions. Validasi tersebut adalah membandingkan berat dari pemodelan dan berat komponen asli. Dimana berat pemodelan footstep holder adalah 0,23 $\mathrm{kg}$ dan berat komponen asli $0,2 \mathrm{~kg}$. Hal tersebut memperlihatkan adanya selisih $0,03 \mathrm{~kg}$ antara pemodelan dan komponen asli. Untuk boundry conditions adalah langkah-langkah sebelum melakukan pembebanan. Diantarnya adalah sebagai berikut:

1. Jumlah nodal pada pemodelan footstep holder dengan Autodesk Inventor Professional 2013 adalah 46028.

2. Jumlah elemen pada pemodelan footstep holder dengan Autodesk Inventor Professional 2013 adalah 27119.

3. Material yang digunakan Aluminium 6061.

4. Fixed constrain, pada pemodelan footstep holder dengan Autodesk Inventor Professional 2013 terdapat dua buah fixed constrain seperti terlihat pada Gambar 4. Dimana warna biru pada Gambar adalah letak dari fixed constrain.Constrain dilakukan karena pada kondisi pemasangan komponen diikat dengan baut frame sepeda motor.

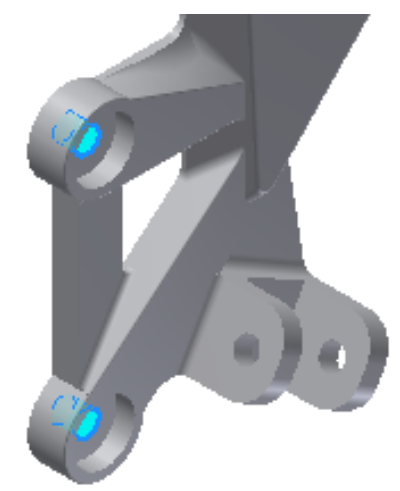

Gambar 4. Lokasi fixed constrain

Pembebanan yang diberikan sebelum melakukan simulasi adalah mengasumsikan beberapa kondisi yang meliputi pembebanan dengan kondisi pengendara duduk dengan kaki bertumpu pada footstep, pengendara berdiri pada footstep, footstep tertabrak dari belakang, footstep tertabrak dari depan motor jatuh kesamping dan motor jatuh kesamping dinaiki dua pengendara. Pembebanan-pembebanan tersebut terlihat pada Gambar 5 sampai 8.

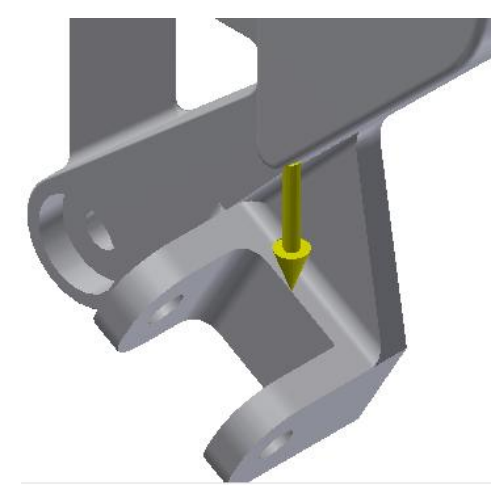

Gambar 5. Pembebanan pada footstep holder pengendara dengan kondisi pengendara duduk dan berdiri pada footstep

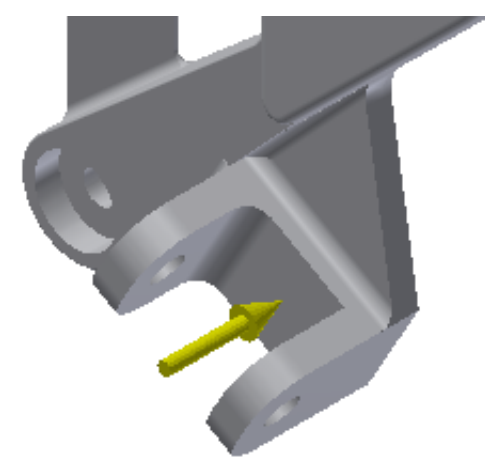

Gambar 6. Pembebanan pada footstep holder pengendara dengan kondisi motor dan motor jatuh kesamping dinaiki dua pengendara 


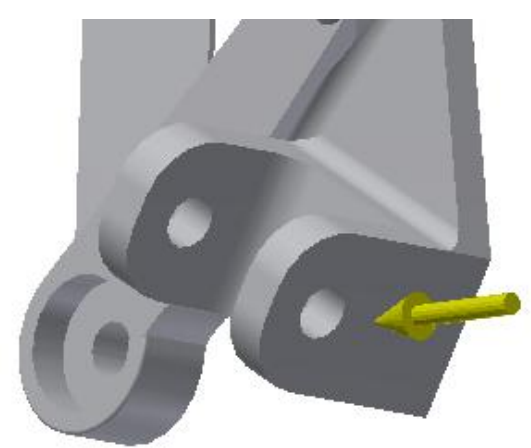

Gambar 7. Pembebanan pada footstep holder pengendara tertabrak dari belakang

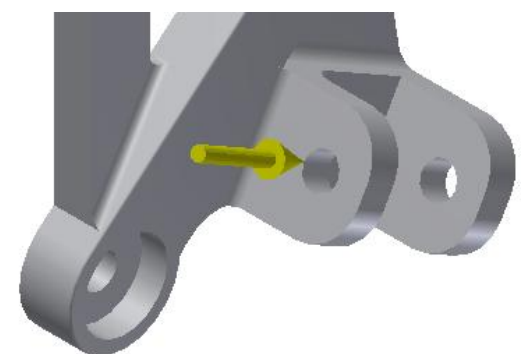

Gambar 8. Pembebanan pada footstep holder pengendara tertabrak dari depan

Besar dari enam pembebanan berbeda-beda, dimulai dari kondisi pembebanan dengan kondisi pengendara duduk dengan kaki bertumpu pada footstep dan pengendara berdiri pada footstep (lihat Gambar 5) dengan arah pembebanan yang sama tapi berbeda pada beban yang diberikan. Untuk kondisi pengendara duduk dengan kaki bertumpu pada footstep diberi beban 98,1N dan kondisi pengendara berdiri pada footstep diberi beban 343,5N.

Pada Gambar 6 meperlihatkan dua kondisi pembebanan yang meliputi kondisi motor jatuh kesamping dan motor jatuh kesamping dengan dua pengendara menaiki motor. Untuk beban yang diberikan pada dua kondisi (Gambar 6) yang pertama kondisi motor jatuh kesamping diberi beban $1265,49 \mathrm{~N}$ dan kondisi motor jatuh kesamping dengan dinaiki dua pengendara diberi beban $2638,89 \mathrm{~N}$.

Kondisi yang terakhir memperlihatkan pembebanan footstep holder tertabrak dari belakang dan depan. Besar dari pembebanan dua kondisi tersebut yang diperlihatkan oleh Gambar 7 dan Gambar 8 adalah 2638,89N.

\section{HASIL DAN PEMBAHASAN}

Hasil simulasi dari berbagai pembebanan pada footstep holder dapat dilihat pada Tabel 1.

Tabel 1. Hasil simulasi

\begin{tabular}{llcccc}
\hline No & \multicolumn{1}{c}{ Kondisi pembebanan } & $\begin{array}{c}\text { Beban } \\
(\mathrm{N})\end{array}$ & $\begin{array}{c}\text { Tegangan von } \\
\text { mises }(\mathrm{MPa})\end{array}$ & $\begin{array}{c}\text { Defleksi } \\
(\mathrm{mm})\end{array}$ & $\begin{array}{c}\text { Faktor } \\
\text { keamanan }\end{array}$ \\
\hline 1 & $\begin{array}{l}\text { Pengendara duduk dengan kaki bertumpu pada } \\
\text { footstep }\end{array}$ & 98,1 & 9,298 & 0,00829 & $>15$ \\
2 & Pengendara berdiri kaki bertumpu pada footstep & 343,35 & 32,54 & 0,02905 & 8,45 \\
3 & Motor jatuh kesamping & 1265,49 & 233,7 & 0,6159 & 1,18 \\
4 & Footstep tertabrak dari belakang & 2638,89 & 246,022 & 0,616 & 1,12 \\
5 & Footstep tertabrak dari depan & 2638,89 & 203 & 0,592 & 1,35 \\
6 & $\begin{array}{l}\text { Motor jatuh kesamping dengan dinaiki dua } \\
\text { pengendara }\end{array}$ & 2638,89 & 468,9 & 1,32 & 0,59 \\
\hline
\end{tabular}

Pada Tabel 1 memperlihatkan perbedaan berbagai hasil simulasi yang meliputi perbedaan tegangan von mises, defleksi dan faktor keamanan. Untuk hasil tegangan von mises maksimal yang paling tinggi pada kondisi motor jatuh kesamping dengan dinaiki dua pengendara seperti terlihat pada Gambar 9. Kondisi ini beresiko menyebabkan terjadinya patah pada bagian daerah lengan footstep holder. 


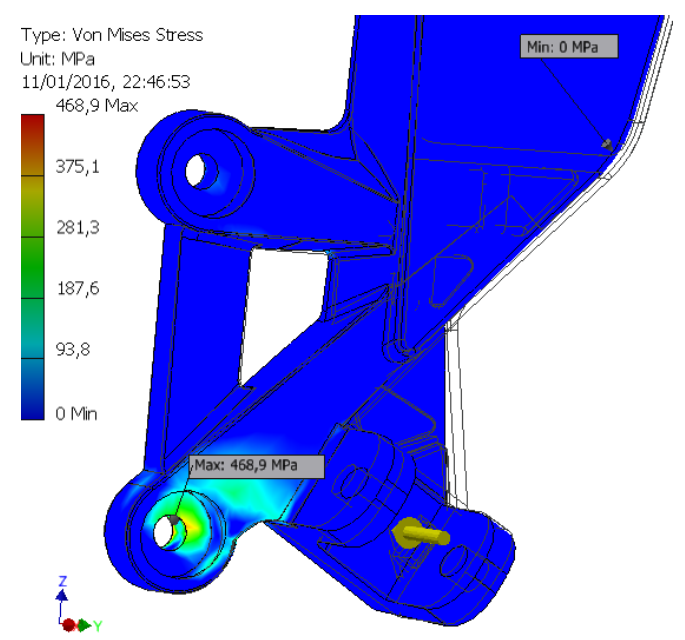

Gambar 9. Tegangan von mises maksimum pada kondisi motor jatuh kesamping dengan dinaiki dua pengendara

Resiko yang dimaksud berdasarkan dari tegangan desain yang dihasilkan dari simulasi pada kondisi pembebanan motor jatuh kesamping dengan dinaiki dua pengendara $(468,9 \mathrm{MPa})$ dimana tegangan tersebut melampaui tegangan titik luluh pada material paduan aluminium 6061 (276MPa).

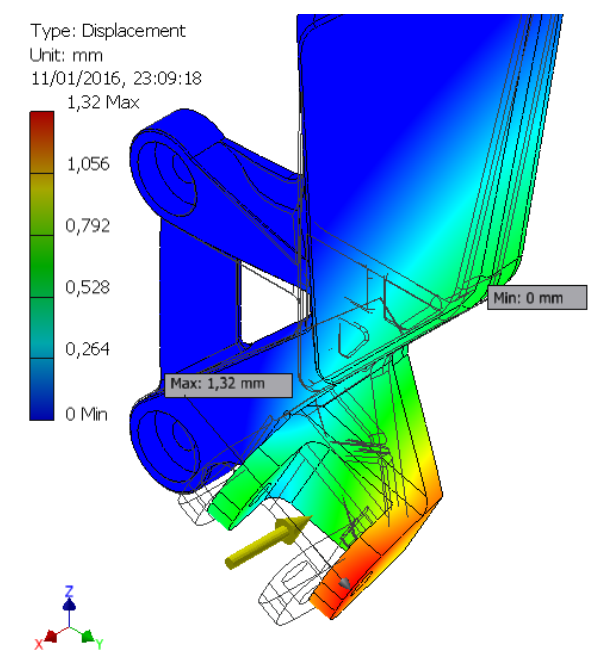

Gambar 10. Defleksi maksimum pada kondisi motor jatuh kesamping dengan dinaiki dua pengendara

Gambar 10 memperlihatkan defleksi maksimum yang paling tinggi pada kondisi motor jatuh kesamping dengan dinaiki dua pengendara $(1,32 \mathrm{~mm})$. Titik defleksi berada pada bagian ujung penjepit footstep. Titik defleksi ini terjadi didasarkan pada daerah yang diberi beban dan jarak beban pada daerah yang dijepit lihat Gambar 5.

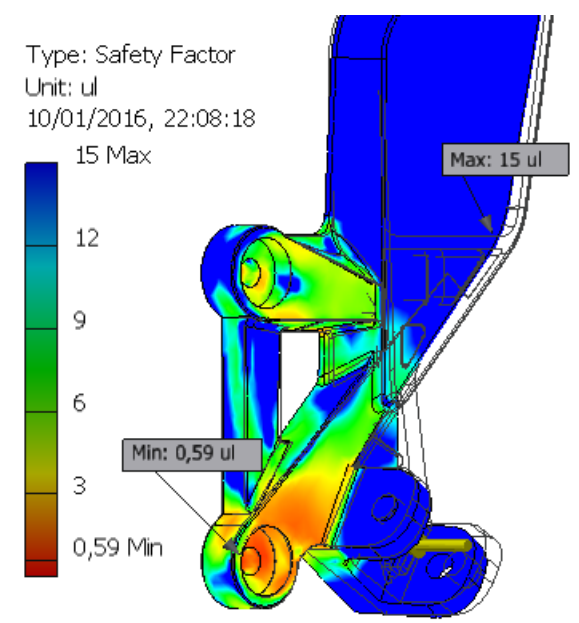

Gambar 11. Faktor keamanan minimum pada kondisi motor jatuh kesamping dengan dinaiki dua pengendara 
Gambar 11 memperlihatkan faktor keamanan minimum pada kondisi pembebanan motor jatuh kesamping dengan dinaiki dua pengendara $(0,59)$ dimana titik kritis minimum berada didaerah penjepit dan lengan footstep holder.

Hasil simulasi pada kondisi motor jatuh kesamping dengan dinaiki dua pengendara menunjukan antara tegangan von mises, defleksi dan faktor keamanan berbanding lurus. Ketika tegangan von mises dan defleksi menghasilkan nilai yang tinggi secara langsung faktor keamanannya juga menjadi kecil. Argumen tersebut didasarkan pada beberapa beberapa hasil simualasi yang telah dilakukan.

Konstruksi footstep holder tersebut sebelumnya telah cukup kuat untuk kondisi-kondisi pembebanan tertentu. Hal ini ditunjukkan pada desain di bagian belakang konstruksi footstep holder dengan adanya tulang-tulang. Tapi tulang-tulang ini belum bisa mendistribusikan tegangan dengan baik.

Pada kondisi pembebanan motor jatuh kesamping dengan dinaiki dua pengendara terjadi konsentrasi tegangan pada lengan dan penjepit footstep (lihat Gambar 11). Daerah pertemuan antara lengan dan penjepit terdapat radius fillet $3 \mathrm{~mm}$ yang belum maksimal dalam mendistribusikan tegangan sehingga membuat tingginya konsentrasi tegangan didaerah tersebut. Radius fillet sendiri digunakan untuk mengalirkan tegangan, penting sangat radius fillet ini untuk meminimalisir terjadinya konsentrasi tegangan [7]. Untuk perbaikan desain konstruksi daerah radius filletnya diperbesar dan daerah-daerah lainnya yang mendapatkan tegangan yang cukup tinggi.

\section{KESIMPULAN}

Berdasarkan analisa simulasi Autodesk Inventor Professional 2013 dihasilkan kesimpulan sebagai berikut:

1. Tegangan maksimum berada pada kondisi pembebanan motor jatuh kesamping dengan dua pengendara dan tegangan maksimum itu adalah 468,9MPa.

2. Defleksi maksimum terjadi pada kondisi pembebanan motor tertabrak dari belakang dengan hasil defleksi sebesar $1,32 \mathrm{~mm}$.

3. Faktor keamanan minimum terjadi pada kondisi pembebanan motor jatuh kesamping dengan dua pengendara dengan nilai 0,59 .

\section{Daftar Pustaka}

[1] Deni, 2013, Biker Rocker, https://www.campurtumpah.wordpress.com/footstep-honda-cb150r-patah/. Diakses : 5 Januari 2016, 13:22.

[2] Tawancy H.M., Hamid A. U., and Abbas N. M., 2004, Practical Engineering Failure Analisys, Marcel Dekker, Inc., 270 Madison Avenue, New York.

[3] Sambas A., 2011, Desain dan Pembuatan Coran Footstep Holder Sepeda Motor Honda Grand Astrea dengan Bahan AC12, Seminar Nasional Teknoin, Yogyakarta.

[4] Saidi R. 2006, Tegangan Maksimum Dudukan Stang Sepeda: Analisis dan Modifikasi Perancangan, Seminar Ilmiah Nasional Komputer dan Sistem Intelijen, Universitas Gunadarma, Depok.

[5] Abidin Z., dan Rama B. R., 2015, Analisa Distribusi Tegangan dan Defleksi Connecting Rod Sepeda Motor 100 CC Mengguanakan Metode Elemen Hingga, Jurnal Rekayasa Mesin, Universitas Sriwijaya.

[6] Waguespack C., 2014, Mastering Autodesk Inventor 2014 and Autodesk LT 2014, John Wiley \& Sons, Inc., 111 River Street, Hoboken, NJ 07030.

[7] Hurst S. K., 2006, Prinsip-Prinsip Perancangan Teknik, Erlangga, Jakarta. 